\title{
Association of Metabolic Syndrome with Aerobic Exercise and LPL rs3779788 Polymorphism in Taiwan Biobank Individuals
}

\author{
Chun-Sheng Hsu ${ }^{\mathrm{I}-4}$ \\ Shin-Tsu Chang $\mathbb{( D}^{1,5,6}$ \\ Oswald Ndi Nfor ${ }^{2}$ \\ Kuan-Jung Lee ${ }^{2}$ \\ Chien-Chang $\mathrm{Ho}^{7,8}$ \\ Chuan-Ching Liu' \\ Shiuan-Shinn Lee ${ }^{2}$ \\ Yung-Po Liaw $\mathbb{D}^{2,9}$ \\ 'Department of Physical Medicine and \\ Rehabilitation, Taichung Veterans General \\ Hospital, Taichung City, 4020I, Taiwan; \\ ${ }^{2}$ Department of Public Health and Institute \\ of Public Health, Chung Shan Medical \\ University, Taichung City, 4020I, Taiwan; \\ ${ }^{3}$ School of Medicine, National Defense Medical \\ Center, Taipei City, I I490, Taiwan; ${ }^{4}$ College of \\ Medicine, National Chung Hsing University, \\ Taichung City, 402, Taiwan; ${ }^{5}$ Department of \\ Physical Medicine and Rehabilitation, Tri- \\ Service General Hospital, School of Medicine, \\ National Defense Medical Centre, Taipei City, \\ I 1490, Taiwan; ${ }^{6}$ Department of Physical \\ Medicine and Rehabilitation, Kaohsiung \\ Veterans General Hospital, Kaohsiung City, \\ 8I34I4, Taiwan; ${ }^{7}$ Department of Physical \\ Education, Fu Jen Catholic University, New \\ Taipei, 24205, Taiwan; ${ }^{8}$ Research and \\ Development Center for Physical Education, \\ Health, and Information Technology, Fu Jen \\ Catholic University, New Taipei, 24205, Taiwan; \\ ${ }^{9}$ Department of Medical Imaging, Chung Shan \\ Medical University Hospital, Taichung City, \\ 4020I, Taiwan
}

Correspondence: Yung-Po Liaw; Shiuan-Shinn Lee

Department of Public Health and Institute of Public Health, Chung Shan Medical University, No. I I0 Sec. I Jianguo N. Road, Taichung City, 4020I, Taiwan Tel +886 424730022 ext. I I 838; +886 424730022 ext. 12185

Fax +886423248I79

Email Liawyp@csmu.edu.tw;

shinn@csmu.edu.tw
Purpose: The Lipoprotein lipase (LPL) gene is a significant contributor to dyslipidemia. It has shown associations with several conditions including atherosclerosis, obesity, and metabolic syndrome (MetS). We assessed the interactive association between MetS and rs3779788 of the $L P L$ gene based on aerobic exercise.

Materials and Methods: Data were available for 7532 Taiwan Biobank (TWB) participants recruited between 2008 and 2016. We used multiple logistic regression to determine the odds ratios (OR) for MetS and their 95\% confident intervals (C.I.). Potential variables included LPL rs3779788, aerobic exercise, sex, age, education, marital status, body mass index (BMI), smoking, alcohol consumption, midnight snacking, vegetarian diet, coffee, dietary fat, and tea drinking.

Results: Aerobic exercise was protective against MetS (OR, 0.858; 95\% C.I., 0.743-0.991). Compared to CC/CT genotype, the OR for developing MetS was 0.875, (95\% C.I., 0.5711.341) in TT individuals. The test for interaction was significant for the rs 3779788 variant and aerobic exercise $(\mathrm{p}=0.0484)$. In our group analyses, the OR for MetS was $0.841(95 \%$ C.I., 0.727-0.974) in CC/CT and 4.076 (95\% C.I., 1.158-14.346) in TT individuals who did aerobic exercise compared to those who did not.

Conclusion: Our study indicated that aerobic exercise improved metabolic syndrome in Taiwanese adults with rs3779788 CC/CT genotype relative to those with TT genotype.

Keywords: polymorphisms, variant, physical activity, metabolic disorders

\section{Introduction}

Metabolic syndrome is characterized by central obesity, hypertension, hyperglycemia, and dyslipidemia based on the guidelines of the National Cholesterol Education Program Adult Treatment Panel III (NCEP-ATP III). ${ }^{1}$ It is a general term for a group of conditions that include cardiovascular disease (CVD), coronary heart disease (CHD), and type 2 diabetes mellitus. ${ }^{2,3}$ According to the World Health Organization (WHO), about 17.9 million people die from CVD each year. In Taiwan, CVD has been the secondleading cause of death over the last decade. ${ }^{4}$ The mortality rate was 87.6 per 100,000 population in $2017 .^{5}$ MetS remains a major risk factor for CVDs. Due to the increasing prevalence rates and several chronic complications, MetS has become one of the major challenges of global public health. ${ }^{6}$

The etiology of MetS is multifactorial and includes genetic and unhealthy lifestyle factors such as smoking, ${ }^{7}$ heavy drinking, ${ }^{8}$ poor diet, and physical inactivity. ${ }^{9}$ Lifestyle modification is essential in preventing MetS and related complications. Regular 
exercise is known to play an important role in cardiovascular health $^{10}$ and glucose metabolism. ${ }^{11}$ Physical activity (especially aerobic exercise) has improved dyslipidemia, insulin resistance, and obesity. ${ }^{12}$ Inverse relationships have also been reported between vigorous exercise and cardiovascular risk factors associated with the MetS. ${ }^{13}$ It has been estimated that physical inactivity could increase the relative risk (RR) of coronary heart disease by $6 \% .^{14}$

Aside from the lifestyle variables, genetic factors are also important in assessing risk factors associated with MetS. ${ }^{15}$ Several polymorphisms in certain genes have been associated with both components of MetS and lifestyle interventions that include exercise. ${ }^{12}$ One such gene is the $L P L$ gene that is located on the human chromosome 8 p22 and is responsible for the metabolism and transport of lipoproteins. Decreased $L P L$ activity has also been associated with several diseases such as atherosclerosis, obesity, dyslipidemia, and Alzheimer's disease. ${ }^{16}$

Polymorphisms in the LPL gene affect not only the expression of $L P L$ but also the relationship between dyslipidemia and insulin resistance. ${ }^{17-19}$ Some of the variants in this gene have also been consistently associated with MetS risk. ${ }^{20}$ Some of the LPL polymorphisms are protective against CAD. Genotypic frequencies of the protective polymorphisms in the $L P L$ gene have significantly decreased in patients with hyperlipidemia. ${ }^{21}$ The $L P L$ gene is modulated by physical activity (PA). ${ }^{22}$ However, it remains unclear how $L P L$ expression is affected by different exercise modalities.

In Taiwan, generalized multifactor dimensionality reduction (GMDR) analyses have already been performed to show the interactive effects of BUD13, CETP, LIPA, smoking, and physical activity on MetS. ${ }^{23}$ But how PA regulates MetS in people with different $L P L$ polymorphisms is still not well understood. In light of this, we examined the relationship between aerobic exercise and $L P L$ rs3779788 polymorphism in relation to MetS among Taiwanese adults.

\section{Methods and Methods \\ Databases}

This was a population-based study. Data were obtained from TWB, a national biomedical research database that contains genetic data of Taiwanese residents. Its objective is to undertake large-scale cohort and case-control studies through a combination of genetic and medical information. All methods were carried out following the relevant guidelines and regulations. Before data collection, all participants had provided written informed consent. The TWB was established in 2005. Data used in this study were collected between 2008 and 2016. The Institutional Review Board of Chung Shan Medical University approved this study (CS2-16114).

\section{Study Participants and Definition of Metabolic Syndrome}

Our study data were from 20,291 TWB participants between the ages 30 and 70 . However, we excluded underweight individuals $(n=633)$ and those with incomplete or missing values $(n=12,126)$. Data included in the final analyses were from 7532 participants. Among them, 655 women and 779 men were identified with MetS. Metabolic syndrome was defined according to the revised NCEP/ATP III criteria proposed by the Health Promotion Administration in Taiwan. ${ }^{24,25}$ In the revised version, the threshold for abdominal obesity had been lowered from 102 to $90 \mathrm{~cm}$ in Taiwanese men and 88 to $80 \mathrm{~cm}$ in women. Participants were defined as having MetS if they had at least three of the following conditions: (1) abdominal obesity (waist circumference: men $\geq 90 \mathrm{~cm}$, women $\geq 80 \mathrm{~cm}$ ); (2) hypertension (systolic blood pressure $\geq 130 \mathrm{mmHg}$ or diastolic blood pressure $\geq 85 \mathrm{mmHg}$ ); (3) hyperglycemia (fasting blood glucose $\geq 100 \mathrm{mg} / \mathrm{dl}$ ); (4) low high-density lipoprotein cholesterol (men $<40 \mathrm{mg} / \mathrm{dl}$, women $<50 \mathrm{mg} / \mathrm{dl}$ ); or (5) high triglyceride (triglyceride $\geq 150 \mathrm{mg} / \mathrm{dl}$ ).

Baseline data included sex, age, education level, marital status, body mass index (BMI), and lifestyle factors like exercise, smoking (never/former and current smoker), alcohol consumption (150 cc per week or regularly for 6 months), midnight snacking (extra snack within an hour before going to bed), coffee drinking (at least three times a week) and tea drinking (at least one time per day).

Information on exercise was extracted from a selfreported questionnaire. Participants chose a maximum of three habitual exercise types. Regular exercisers were people who had at least 3 sessions of exercise a week, each session lasting for at least 30 minutes in the last three months. Aerobic exercises studied included jogging, strolling, swimming, yoga, Taijiquan, biking, aerobic dance, and ballroom dance. Participants did at most 3 types of aerobic exercises per week. We assessed dietary fat based on 12 questions (with responses to each question based on a five-point scale; $1=$ never, $2=$ seldom, $3=$ sometimes, $4=$ frequently, 
and $5=$ always), scored 0 to 60 , with a higher score indicating greater consumption of a fat diet over the past month.

\section{Genetic Variant Selection/Genotyping}

We selected rs3779788 in the $L P L$ gene after reviewing the literature. The Biobank samples had been genotyped in Academia Sinica using the custom Axiom Genome-Wide Array Plate system (Affymetrix, Santa Clara, CA, USA). The biobank samples were included in the analysis model if the call rates were greater than $10 \%$. The rs3779788 polymorphism was in Hardy-Weinberg equilibrium ( $p$ $\geq 0.05$ ) and the minor allele frequency (MAF) was $\geq 0.05$.

\section{Statistical Analysis}

Data processing and statistical analyses were conducted using the PLINK 1.09 beta and SAS 9.4 software (SAS Institute, Cary, NC, USA). Data with normal distributions were analyzed by the Chi-square test. Normally distributed variables were presented as numbers and percentages. A p-value less than 0.05 was considered statistically significant. To estimate the genotypic association of the rs3779788 with MetS, multivariate logistic regression models were used to evaluate the genotype-specific ORs and their 95\% C.I. Recessive models were used to determine the interaction between aerobic exercise and rs3779788 on MetS risk.

\section{Results}

Overall, 7532 participants met the inclusion criteria of the study (Table 1). Among participants with MetS ( $\mathrm{n}=$ 1434), 779 were men and 655 were women. Of these participants, 1401 (97.70\%) were those with rs3779788 CC/CT genotype of rs3779788 while 33 (2.30\%) were those with the TT genotype. Of the 6098 individuals with no MetS, 5943 (97.46\%) were those with CC/CT, and $155(2.54 \%)$ were those with the TT genotype. There were no significant differences between participants with and without MetS based on genotype distributions $(p=0.5993)$. After adjusting for confounders (Table 2), the odds of having MetS was significantly lower among those who did aerobic exercise regularly $(\mathrm{OR}=0.858,95 \%$ C.I. $=0.743-0.991)$ compared with non-exercisers. The odds ratio for MetS was $3.712(95 \%$ C.I. $=3.122-4.414)$ in overweight, $13.681(95 \%$ C.I. $=11.464-16.327)$ in obese compared to normal-weight individuals, 1.429
Table I Demographic Characteristics of Study Participants

\begin{tabular}{|c|c|c|c|}
\hline & No MetS & MetS & \multirow[t]{2}{*}{ p-value } \\
\hline & $(n=6098)$ & $(n=1434)$ & \\
\hline rs3779788, n (\%) & & & 0.5993 \\
\hline $\mathrm{CC} / \mathrm{CT}$ & $5943(97.46)$ & I40I (97.70) & \\
\hline TT & I55 (2.54) & $33(2.30)$ & \\
\hline Exercise, n (\%) & & & 0.9613 \\
\hline No & $4074(66.8 I)$ & $959(66.88)$ & \\
\hline Aerobic exercise & 2024 (33.19) & $475(33.12)$ & \\
\hline Sex, n (\%) & & & $<0.0001$ \\
\hline Female & 3352 (54.97) & $655(45.68)$ & \\
\hline Male & $2746(45.03)$ & 779 (54.32) & \\
\hline Age, yr & & & $<0.0001$ \\
\hline $30-40$ & I878 (30.80) & $226(15.76)$ & \\
\hline $4 I-50$ & $1812(29.71)$ & $365(25.45)$ & \\
\hline $51-60$ & I58I (25.93) & $507(35.36)$ & \\
\hline $61-70$ & $827(13.56)$ & $336(23.43)$ & \\
\hline Education, $\mathrm{n}(\%)$ & & & $<0.0001$ \\
\hline University \& above & $3330(54.61)$ & $566(39.47)$ & \\
\hline Senior High School & 1915 (31.40) & $509(35.50)$ & \\
\hline Junior High School & $507(8.31)$ & $188(13.11)$ & \\
\hline Elementary \& below & $346(5.67)$ & I7| (1I.92) & \\
\hline Marital status, n (\%) & & & $<0.0001$ \\
\hline Married & 4781 (78.40) & II 40 (79.50) & \\
\hline Single & 706 (11.58) & II 3 (7.88) & \\
\hline Divorced & $391(6.4 I)$ & $108(7.53)$ & \\
\hline Widowed & $220(3.6 I)$ & $73(5.09)$ & \\
\hline BMI $\left(\mathrm{kg} / \mathrm{m}^{2}\right)$ & & & $<0.0001$ \\
\hline Normal & $3440(56.4 I)$ & $227(15.83)$ & \\
\hline Overweight & $1830(30.01)$ & $488(34.03)$ & \\
\hline Obese & $828(13.58)$ & $719(50.14)$ & \\
\hline Smoking, n (\%) & & & $<0.0001$ \\
\hline Never & 4793 (78.60) & $994(69.32)$ & \\
\hline Former & $663(10.87)$ & $199(13.88)$ & \\
\hline Current & $642(10.53)$ & $24 I(\mid 6.8 I)$ & \\
\hline Alcohol Drinking, n (\%) & & & $<0.0001$ \\
\hline Never & 5555 (91.10) & $1207(84.17)$ & \\
\hline Former & $139(2.28)$ & $80(5.58)$ & \\
\hline Current & $404(6.63)$ & $147(10.25)$ & \\
\hline Midnight snacking, n (\%) & & & 0.0118 \\
\hline No & 4211 (69.06) & $94 \mid(65.62)$ & \\
\hline Yes & I 887 (30.94) & $493(34.38)$ & \\
\hline Coffee drinking, n (\%) & & & $<0.0001$ \\
\hline No & 4012 (65.79) & $1024(7 I .4 I)$ & \\
\hline Yes & $2086(34.21)$ & $410(28.59)$ & \\
\hline
\end{tabular}

(Continued) 
Table I (Continued).

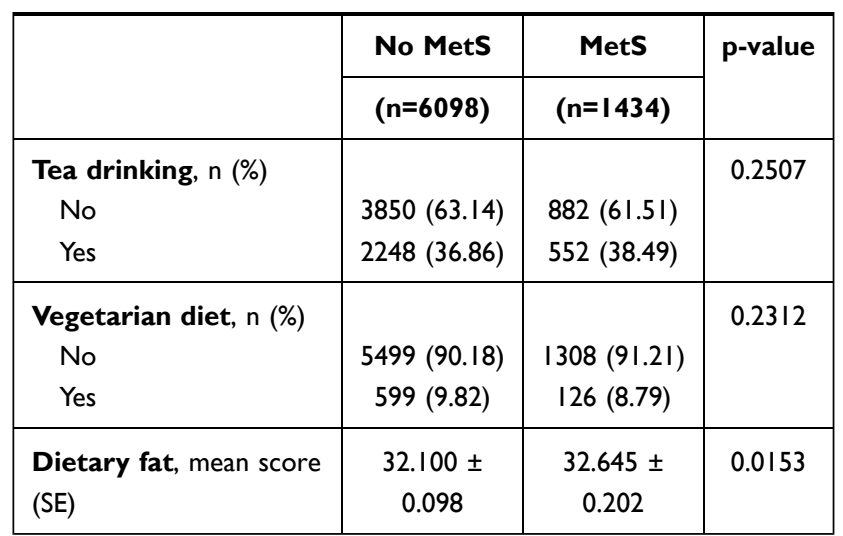

Note: Data were presented as numbers and percentages. $\mathrm{CC} / \mathrm{CT}$ and TT are the rs3779788 genotypes.

Abbreviations: MetS, metabolic syndrome; BMI, body mass index; yr, year.

$(95 \%$ C.I. $=1.154-1.770)$ in current compared to nonsmokers, and $1.454(95 \%$ C.I. $=1.042-2.030)$ in former compared to non-alcohol drinker. Also associated with increased odds of having MetS were the higher age groups: 41 to 50 year (OR, $1.634 ; 95 \%$ C.I. $=1.334$ 2.002), 51 to 60 year (OR, 2.724; 95\% C.I. $=210-3.358$ ), and the 61-70 year age group (OR, 3.765; 95\% C.I. $=2.960-4.789$ ), respectively compared to the 30 to 40 age group.

There was an interaction between rs3779788 and aerobic exercise $(\mathrm{p}=0.0484)$. In a separate multivariable model stratified by rs3779788 genotypes (Table 3), the ORs were 0.841 in those with the CC/CT genotype (95\% C.I. $=0.727-$ $0.974)$ and $4.076(95 \%$ C.I. $=1.158-14.346)$ in those with TT genotype who were engaged in aerobic exercise compared to their inactive counterparts. In another model with the "no exercise and CC/TT" group representing the reference group (Table 4), the OR was 0.841 (95\% C.I. $=0.727-$ 0.973 ) in aerobic exercise and $\mathrm{CC} / \mathrm{CT}$ individuals. No significant differences were observed in TT individuals.

\section{Discussion}

To our understanding, our study is the first to determine the links between $L P L$ variant and aerobic exercise in relation to MetS in Taiwan. We observed a significant interaction between $L P L$ rs3779788 and aerobic exercise. Our stratified analyses indicated that aerobic exercise was protective against MetS in people with $\mathrm{CC} / \mathrm{CT}$ but not TT genotype. Aerobic exercise is known to improve MetS by enhancing glucose transport and GLUT4 translocation. ${ }^{26}$ However, the mechanistic bases for the links between
Table 2 Odds Ratios for MetS Among Study Participants

\begin{tabular}{|c|c|c|}
\hline & OR & 95\% C.I. \\
\hline \multicolumn{3}{|l|}{ rs3779788 (ref: CC/CT) } \\
\hline TT & 0.875 & $0.57|-| .34 \mid$ \\
\hline \multicolumn{3}{|l|}{ Exercise (ref: No) } \\
\hline Aerobic exercise & 0.858 & $0.743-0.991$ \\
\hline \multicolumn{3}{|l|}{ Sex (ref: Female) } \\
\hline Male & 0.960 & $0.817-1.129$ \\
\hline \multicolumn{3}{|l|}{ Age (ref: $30-40$ ) } \\
\hline $4 I-50$ & 1.634 & $1.334-2.002$ \\
\hline $5 I-60$ & 2.724 & $2.210-3.358$ \\
\hline $6 I-70$ & 3.765 & $2.960-4.787$ \\
\hline \multicolumn{3}{|l|}{$\begin{array}{l}\text { Education (ref: University \& } \\
\text { above) }\end{array}$} \\
\hline Senior High School & 1.243 & I.067-1.448 \\
\hline Junior High School & 1.388 & $1.111-1.732$ \\
\hline Elementary \& below & 1.434 & $1.118-1.840$ \\
\hline \multicolumn{3}{|l|}{ Marital status (ref: Married) } \\
\hline Single & 1.026 & $0.804-1.309$ \\
\hline Divorced & 1.238 & $0.958-1.958$ \\
\hline Widowed & 1.016 & $0.739-1.397$ \\
\hline \multicolumn{3}{|l|}{ BMI, kg/m² (ref: Normal) } \\
\hline Overweight & 3.712 & $3.122-4.414$ \\
\hline Obese & $|3.68|$ & II.464-16.327 \\
\hline \multicolumn{3}{|l|}{ Smoking (ref: Never) } \\
\hline Former & 0.869 & $0.702-1.076$ \\
\hline Current & 1.429 & $1.154-1.770$ \\
\hline \multicolumn{3}{|l|}{ Alcohol Drinking (ref: Never) } \\
\hline Former & 1.454 & $1.042-2.030$ \\
\hline Current & 1.256 & $0.988-1.598$ \\
\hline
\end{tabular}

Note: Adjusted for midnight snacking, coffee and tea consumption, vegetarian diet, and dietary fat.

Abbreviations: MetS, metabolic syndrome; BMI, body mass index; OR, odds ratio; ref, reference.

rs3779788, aerobic exercise, and MetS remain to be determined.

Several polymorphisms of the lipoprotein metabolismassociated genes have shown significant associations with different components of MetS or related traits. ${ }^{27}$ Among them, APOA5 rs662799, ${ }^{28}$ BUD13 rs11216126, and rs180349, ${ }^{29}$ CD36 rs13230419, rs13246513, rs3173804, rs7755 and rs3211850) ${ }^{30}$ variants were associated with increased risk of MetS while CD36 rs3211938 $8^{30}$ and GCK rs $1799884^{28}$ appeared to be protective. LPL is an enzyme that promotes hydrolysis of lipoprotein and regulates various aspects of metabolism, such as energy balance, insulin action, body weight regulation, and 
Table 3 Odd Ratios for MetS Among Individuals with Rs3779788 Genotypes

\begin{tabular}{|c|c|c|c|c|}
\hline & \multicolumn{2}{|c|}{$\mathrm{CC} / \mathrm{CT}$} & \multicolumn{2}{|c|}{ TT } \\
\hline & OR & 95\% C.I. & OR & $95 \%$ C.I. \\
\hline \multicolumn{5}{|l|}{ Exercise (ref: No) } \\
\hline Aerobic exercise & $0.84 I$ & $0.727-0.974$ & 4.076 & $1.158-14.346$ \\
\hline \multicolumn{5}{|l|}{ Sex (ref: Female) } \\
\hline Male & 0.986 & $0.838-1.161$ & 0.105 & $0.022-0.507$ \\
\hline \multicolumn{5}{|l|}{ Age (ref: $30-40$ ) } \\
\hline $4 I-50$ & 1.620 & $1.320-1.988$ & 2.334 & $0.416-13.092$ \\
\hline $51-60$ & 2.702 & $2.187-3.338$ & 3.836 & $0.624-23.573$ \\
\hline $6 \mathrm{I}-70$ & 3.639 & $2.852-4.642$ & 17.570 & $2.466-125.193$ \\
\hline \multicolumn{5}{|c|}{ Education (ref: University \& above) } \\
\hline Senior High School & 1.243 & $1.065-1.45 \mid$ & 1.142 & $0.331-3.948$ \\
\hline Junior High School & 1.389 & $1.110-1.738$ & 2.775 & $0.375-20.545$ \\
\hline Elementary \& below & 1.487 & $1.155-1.914$ & 0.731 & $0.078-6.889$ \\
\hline \multicolumn{5}{|c|}{ Marital status (ref: Married) } \\
\hline Single & 1.006 & $0.785-1.289$ & 2.369 & $0.413-13.594$ \\
\hline Divorced & 1.234 & $0.954-1.597$ & 1.098 & $0.086-14.033$ \\
\hline Widowed & 1.068 & $0.773-1.475$ & 0.169 & $0.012-2.368$ \\
\hline \multicolumn{5}{|l|}{ BMI, $\mathrm{kg} / \mathrm{m}^{2}$ (ref: Normal) } \\
\hline Overweight & 3.753 & $3.149-4.473$ & 2.607 & $0.740-9.185$ \\
\hline Obese & 13.684 & II.439-16.370 & 42.519 & $9.291-194.577$ \\
\hline \multicolumn{5}{|l|}{ Smoking (ref: Never) } \\
\hline Former & 0.857 & $0.691-1.064$ & 3.021 & $0.400-22.809$ \\
\hline Current & 1.399 & $1.128-1.737$ & 25.386 & $2.747-234.632$ \\
\hline \multicolumn{5}{|c|}{ Alcohol Drinking (ref: Never) } \\
\hline Former & 1.515 & $1.082-2.121$ & 0.130 & $0.005-3.150$ \\
\hline Current & 1.256 & $0.984-1.604$ & 0.726 & $0.100-5.291$ \\
\hline
\end{tabular}

Note: Adjusted for midnight snacking, coffee and tea consumption, vegetarian diet, and dietary fat.

Abbreviations: MetS, metabolic syndrome; BMI, body mass index; OR, odds ratio; ref, reference.

atherosclerosis. ${ }^{31}$ The $L P L$ gene spans about $30 \mathrm{~kb}$ that is located on chromosome $8 \mathrm{p} 22$ and consists of 10 exons and 9 introns. $^{32}$ This gene is primarily expressed in the heart, muscle, and adipose tissue. ${ }^{33}$ Several mutations were found in the $L P L$ gene which could cause $L P L$ deficiency. $^{34}$

Several studies have shown that polymorphisms of the $L P L$ gene may occur in at least 88 locations in the human DNA and mutations could change the role and function of the LPL enzyme related to MetS risk. ${ }^{32,35-37}$ A study indicated that about $20 \%$ of patients with hypertriglyceridemia are carriers of common $L P L$ gene mutations associated with hyperlipidemia (HLP). ${ }^{38}$ Studies with the young Asian Indian population reported significant associations between LPL gene polymorphisms (rs1800590) and MetS, and the frequency of the minor allele $(\mathrm{G})$ was higher in patients with MetS (OR, 2.72; 95\% CI, 1.078.16). ${ }^{35}$ Besides, genetic variants of the $L P L$ promoter are associated with the alternation in lipid metabolism which may lead to obesity and type 2 diabetes. ${ }^{36,37,39}$ In the Framingham Offspring Study, both rs1801177 and rs268 variants in the $L P L$ gene were associated with changes in lipoprotein and increased risk of atherosclerosis. ${ }^{40} \mathrm{~A}$ few studies found that rs3779788 SNP in the LPL gene was related to coronary artery disease and blood lipid. ${ }^{41,42}$

Physical inactivity has been associated with certain unhealthy effects worldwide: it could lower LCAT (lecithin-cholesterol acyltransferase) which transfers free fatty acids to HDL. ${ }^{14,43}$ Different types of exercise will influence the human body in various ways. For instance, low-to-moderate intensity cardiorespiratory exercise was reported to improve components of MetS in 
Table 4 Odds of Having MetS Based on Aerobic Exercise and Rs3779788 Genotypes

\begin{tabular}{|c|c|c|}
\hline & OR & 95\% C.I. \\
\hline \multicolumn{3}{|c|}{ Aerobic exercise and rs3779788 (ref: no exercise and CC/CT) } \\
\hline No exercise and TT & 0.636 & $0.366-1.107$ \\
\hline Aerobic exercise and $\mathrm{CC} / \mathrm{CT}$ & 0.841 & $0.727-0.973$ \\
\hline Aerobic exercise and TT & 1.282 & $0.659-2.496$ \\
\hline \multicolumn{3}{|l|}{ Sex (ref: Female) } \\
\hline Male & 0.957 & $0.815-1.125$ \\
\hline \multicolumn{3}{|l|}{ Age (ref: $30-40$ ) } \\
\hline $4 I-50$ & 1.634 & $1.334-2.001$ \\
\hline $5 I-60$ & 2.722 & $2.209-3.356$ \\
\hline $61-70$ & 3.765 & $2.960-4.789$ \\
\hline \multicolumn{3}{|l|}{ Education (ref: University \& above) } \\
\hline Senior High School & 1.243 & $1.067-1.448$ \\
\hline Junior High School & 1.395 & I.II7-I.742 \\
\hline Elementary \& below & $\mathrm{I} .44 \mathrm{I}$ & $1.122-1.850$ \\
\hline \multicolumn{3}{|l|}{ Marital status (ref: Married) } \\
\hline Single & 1.028 & $0.806-1.312$ \\
\hline Divorced & 1.236 & $0.957-1.596$ \\
\hline Widowed & 1.010 & $0.734-1.389$ \\
\hline \multicolumn{3}{|l|}{ BMI, kg/m² (ref: Normal) } \\
\hline Overweight & 3.720 & $3.128-4.423$ \\
\hline Obese & 13.722 & II.497-16.377 \\
\hline \multicolumn{3}{|l|}{ Smoking (ref: Never) } \\
\hline Former & 0.873 & $0.705-1.08 \mid$ \\
\hline Current & 1.439 & $1.162-1.783$ \\
\hline \multicolumn{3}{|l|}{ Alcohol Drinking (ref: Never) } \\
\hline Former & 1.467 & $\mathrm{I} .05 \mathrm{I}-2.048$ \\
\hline Current & 1.257 & $0.988-1.599$ \\
\hline
\end{tabular}

Note: Adjusted for midnight snacking, coffee and tea consumption, vegetarian diet, and dietary fat. Abbreviations: MetS, metabolic syndrome; BMI, body mass index; OR, odds ratio; ref, reference.

postmenopausal women. ${ }^{44}$ Dynamic endurance training also has beneficial effects on MetS-related risk factors. ${ }^{13}$ Many studies found that aerobic exercise played an essential role in decreasing MetS risk. ${ }^{45-47}$ In a previous study, resistance exercise helped lower MetS risk, independent of aerobic exercise. ${ }^{48}$ However, according to other researchers, the decrease in MetS risk is more substantial when aerobic exercise is combined with resistance exercise. ${ }^{48-50}$

In our primary analysis, we found that aerobic exercise was protective against MetS ( $\mathrm{OR}=0.858$; 95\% C.I., $0.743-$ 0.991). However, after stratification by rs3779788 genotypes, we realized that the odds for MetS were lower among CC/CT (OR=0.841; 95\% C.I., 0.727-0.974) but not TT individuals $(\mathrm{OR}=4.076 ; 95 \%$ C.I., 1.158-14.346). In other words, the association between Mets and exercise differed across the rs3779388 genotypes. However, the mechanisms behind these associations are not fully understood. More studies are needed to support these findings. In the current study, we also found that well-known risk factors such as older age, obesity, overweight, and smoking were associated with increased odds of having MetS.

Of note, we acknowledge the following limitations. First, causal conclusions could not be drawn considering that the study design is observational. Second, we collected our lifestyle data using self-reported questionnaires. This may have introduced recall bias. Next, our database contained no information on exercise intensity, saturated fatty acids, trans-fatty acids, simple carbohydrates, and medication history. 


\section{Conclusion}

In conclusion, we observed a relationship between MetS and an $L P L$ variant (rs3779788) among Taiwanese adults 30 to 70 years old. We found that aerobic exercise was protective against MetS among those with the rs3779788 $\mathrm{CC} / \mathrm{CT}$ genotype compared to those with TT genotype.

\section{Funding}

This study was supported by the Ministry of Science and Technology, Taiwan (MOST 107-2627-M-040-002, 1082621-M-040-001, and 109-2121-M-040-002).

\section{Disclosure}

The authors report no conflicts of interest in this work.

\section{References}

1. Panel On Detection, Evaluation, And Treatment Of High Blood Cholesterol In Adults E. Executive summary of the third report of The National Cholesterol Education Program (NCEP) expert panel on detection, evaluation, and treatment of high blood cholesterol in adults (Adult Treatment Panel III). JAMA. 2001;285(19):2486-2497. doi:10.1001/ jama.285.19.2486

2. Kassi E, Pervanidou P, Kaltsas G, Chrousos G. Metabolic syndrome: definitions and controversies. BMC Med. 2011;9(1):48. doi:10.1186/ 1741-7015-9-48

3. Stancakova A, Laakso M. Genetics of metabolic syndrome. Rev Endocr Metab Disord. 2014;15(4):243-252. doi:10.1007/s11154014-9293-9

4. Welfare MoHa. Statistics of Causes of Death; 2017. Available online: https://www.mohw.gov.tw/np-128-2.html. Accessed December 31, 2019.

5. Welfare MoHa. Statistics of Causes of Death; 2018. Available online: https://www.mohw.gov.tw/np-128-2.html. Accessed December 24, 2019.

6. Eckel RH, Grundy SM, Zimmet PZ. The metabolic syndrome. Lancet. 2005;365(9468):1415-1428. doi:10.1016/S0140-6736(05) 66378-7

7. Oh SW, Yoon YS, Lee ES, et al. Association between cigarette smoking and metabolic syndrome: the Korea national health and nutrition examination survey. Diabetes Care. 2005;28 (8):2064-2066. doi:10.2337/diacare.28.8.2064

8. Fan AZ, Russell M, Dorn J, et al. Lifetime alcohol drinking pattern is related to the prevalence of metabolic syndrome. The Western New York Health Study (WNYHS). Eur J Epidemiol. 2006;21 (2):129-138. doi:10.1007/s10654-005-5457-y

9. Katzmarzyk PT, Leon AS, Wilmore JH, et al. Targeting the metabolic syndrome with exercise: evidence from the HERITAGE family study Med Sci Sports Exerc. 2003;35(10):1703-1709. doi:10.1249/01. MSS.0000089337.73244.9B

10. Myers J. Exercise and cardiovascular health. Circulation. 2003;107 (1):e2-e5. doi:10.1161/01.CIR.0000048890.59383.8D

11. Riddell M, Perkins BA. Exercise and glucose metabolism in persons with diabetes mellitus: perspectives on the role for continuous glucose monitoring. J Diabetes Sci Technol. 2009;3(4):914-923. doi:10.1177/193229680900300439

12. Fenwick PH, Jeejeebhoy K, Dhaliwal R, et al. Lifestyle genomics and the metabolic syndrome: a review of genetic variants that influence response to diet and exercise interventions. Crit Rev Food Sci Nutr. 2019;59(13):2028-2039. doi:10.1080/10408398.2018.1437022
13. Pattyn N, Cornelissen VA, Eshghi SR, Vanhees L. The effect of exercise on the cardiovascular risk factors constituting the metabolic syndrome: a meta-analysis of controlled trials. Sports Med. 2013;43 (2):121-133. doi:10.1007/s40279-012-0003-z

14. Lee IM, Shiroma EJ, Lobelo F, Puska P, Blair SN, Katzmarzyk PT. Effect of physical inactivity on major non-communicable diseases worldwide: an analysis of burden of disease and life expectancy. Lancet. 2012;380(9838):219-229.

15. Castellano-Castillo D, Moreno-Indias I, Fernandez-Garcia JC, et al. Adipose tissue LPL methylation is associated with triglyceride concentrations in the metabolic syndrome. Clin Chem. 2018;64 (1):210-218. doi:10.1373/clinchem.2017.277921

16. Mead JR, Irvine SA, Ramji DP. Lipoprotein lipase: structure, function, regulation, and role in disease. $J$ Mol Med. 2002;80 (12):753-769. doi:10.1007/s00109-002-0384-9

17. Hölzl B, Iglseder B, Sandhofer A, et al. Insulin sensitivity is impaired in heterozygous carriers of lipoprotein lipase deficiency. Diabetologia. 2002;45(3):378-384. doi:10.1007/s00125-001-0771-8

18. Ma YQ, Thomas GN, Ng MC, Critchley JA, Chan JC, Tomlinson B. The lipoprotein lipase gene HindIII polymorphism is associated with lipid levels in early-onset type 2 diabetic patients. Metabolism. 2003;52(3):338-343. doi:10.1053/meta.2003.50053

19. Goodarzi MO, Guo X, Taylor KD, et al. Lipoprotein lipase is a gene for insulin resistance in Mexican Americans. Diabetes. 2004;53 (1):214-220. doi:10.2337/diabetes.53.1.214

20. Cahua-Pablo J, Cruz M, Méndez-Palacios A, et al. Polymorphisms in the LPL and CETP genes and haplotype in the ESR1 gene are associated with metabolic syndrome in women from southwestern Mexico. Int J Mol Sci. 2015;16(9):21539-21554. doi:10.3390/ijms160921539

21. Wung S-F, Kulkarni MV, Pullinger CR, Malloy MJ, Kane JP, Aouizerat BE. The lipoprotein lipase gene in combined hyperlipidemia: evidence of a protective allele depletion. Lipids Health Dis. 2006;5(1):19. doi:10.1186/1476-511X-5-19

22. Seip RL, Angelopoulos TJ, Semenkovich CF. Exercise induces human lipoprotein lipase gene expression in skeletal muscle but not adipose tissue. Am J Physiol Endocrinol Metab. 1995;268(2):E229E236. doi:10.1152/ajpendo.1995.268.2.E229

23. Lin E, Kuo P-H, Liu Y-L, Yang AC, Kao C-F, Tsai S-J. Association and interaction of APOA5, BUD13, CETP, LIPA and health-related behavior with metabolic syndrome in a Taiwanese population. Sci Rep. 2016;6(1):36830. doi:10.1038/srep36830

24. Chen Y-F, Lin Y-A, Yeh W-C, et al. The association between metabolic syndrome and elevated alanine aminotransferase levels in an indigenous population in Northern Taiwan: a community-based and cross-sectional study. Evid Based Complement Alternat Med. 2020;2020:1-9. doi:10.1155/2020/6612447

25. The criteria for adult metabolic syndrome; 2007. Available from: https://www.hpa.gov.tw/Pages/Detail.aspx?nodeid=639\&pid=1219. Accessed August 31, 2021.

26. Myers J, Kokkinos P, Nyelin E. Physical activity, cardiorespiratory fitness, and the metabolic syndrome. Nutrients. 2019;11(7):1652. doi:10.3390/nu11071652

27. Ukkola O, Bouchard C. Clustering of metabolic abnormalities in obese individuals: the role of genetic factors. Ann Med. 2001;33 (2):79-90. doi:10.3109/07853890109002062

28. Yamada Y, Kato K, Hibino T, et al. Prediction of genetic risk for metabolic syndrome. Atherosclerosis. 2007;191(2):298-304. doi:10.1016/j.atherosclerosis.2006.05.035

29. Jeong SW, Chung M, Park S-J, Cho SB, Hong K-W. Genome-wide association study of metabolic syndrome in Koreans. Genomics Inform. 2014;12(4):187. doi:10.5808/GI.2014.12.4.187

30. Love-Gregory L, Sherva R, Sun L, et al. Variants in the CD36 gene associate with the metabolic syndrome and high-density lipoprotein cholesterol. Hum Mol Genet. 2008;17(11):1695-1704. doi:10.1093/ $\mathrm{hmg} / \mathrm{ddn} 060$ 
31. Wang H, Eckel RH. Lipoprotein lipase: from gene to obesity. Am J Physiol Endocrinol Metab. 2009;297(2):E271-E288. doi:10.1152/ ajpendo. 90920.2008

32. Alinaghian N, Abdollahi E, Torab M, Khodaparast M, Zamani F, Rahimi-Moghaddam P. Gender-related relation between metabolic syndrome and S447X and HindIII polymorphisms of lipoprotein lipase gene in northern Iran. Gene. 2019;706:13-18. doi:10.1016/j. gene.2019.04.069

33. Information(NCBI) NCfB. LPL lipoprotein lipase; 2020. Available from: https://www.ncbi.nlm.nih.gov/gene/4023. Accessed August 31, 2021.

34. Rahalkar AR, Giffen F, Har B, et al. Novel LPL mutations associated with lipoprotein lipase deficiency: two case reports and a literature review. Can J Physiol Pharmacol. 2009;87(3):151-160. doi:10.1139/ Y09-005

35. Ranjith N, Pegoraro RJ, Rom L. Lipid profiles and associated gene polymorphisms in young Asian Indian patients with acute myocardial infarction and the metabolic syndrome. Metab Syndr Relat Disord. 2009;7(6):571-578. doi:10.1089/met.2009.0015

36. Radha V, Vimaleswaran KS, Ayyappa KA, Mohan V. Association of lipoprotein lipase gene polymorphisms with obesity and type 2 diabetes in an Asian Indian population. Int J Obes. 2007;31(6):913.

37. Jemaa R, Tuzet S, Portos C, Betoulle D, Apfelbaum M, Fumeron F. Lipoprotein lipase gene polymorphisms: associations with hypertriglyceridemia and body mass index in obese people. Int $J$ Obes Relat Metab Disord. 1995;19(4):270-274.

38. Gehrisch S. Common mutations of the lipoprotein lipase gene and their clinical significance. Curr Atheroscler Rep. 1999;1(1):70-78. doi:10.1007/s11883-999-0052-4

39. Muñoz-Barrios S, Guzmán-Guzmán IP, Muñoz-Valle JF, SalgadoBernabé AB, Salgado-Goytia L, Parra-Rojas I. Association of the HindIII and S447X polymorphisms in LPL gene with hypertension and type 2 diabetes in Mexican families. Dis Markers. 2012;33 (6):313-320. doi:10.1155/2012/673452

40. Kastelein JJ, Ordovas JM, Wittekoek ME, et al. Two common mutations (D9N, N291S) in lipoprotein lipase: a cumulative analysis of their influence on plasma lipids and lipoproteins in men and women. Clin Genet. 1999;56(4):297-305. doi:10.1034/j.1399-0004.1999. 560407.x
41. Cheema AN, Rosenthal SL, Ilyas Kamboh M. Proficiency of data interpretation: identification of signaling SNPs/specific loci for coronary artery disease. Database (Oxford). 2017;2017. doi:10.1093/ database/bax078

42. Zhang X, Johnson AD, Hendricks AE, et al. Genetic associations with expression for genes implicated in GWAS studies for atherosclerotic cardiovascular disease and blood phenotypes. Hum Mol Genet. 2014;23(3):782-795. doi:10.1093/hmg/ddt461

43. McMurray RG, Bo Andersen L. The influence of exercise on metabolic syndrome in youth: a review. Am J Lifestyle Med. 2010;4 (2):176-186. doi:10.1177/1559827609351234

44. Earnest CP, Johannsen NM, Swift DL, Lavie CJ, Blair SN, Church TS. Dose effect of cardiorespiratory exercise on metabolic syndrome in postmenopausal women. Am J Cardiol. 2013;111 (12):1805-1811. doi:10.1016/j.amjcard.2013.02.037

45. Okura T, Nakata Y, Ohkawara K, et al. Effects of aerobic exercise on metabolic syndrome improvement in response to weight reduction. Obesity. 2007;15(10):2478-2484. doi:10.1038/oby.2007.294

46. Pourranjbar M, Arabnejad N, Naderipour K, Rafie F. Effects of aerobic exercises on serum levels of myonectin and insulin resistance in obese and overweight women. J Med Life. 2018;11(4):381-386.

47. Morales-Palomo F, Ramirez-Jimenez M, Ortega JF, Mora-Rodriguez R. Effectiveness of aerobic exercise programs for health promotion in metabolic syndrome. Med Sci Sports Exerc. 2019;51(9):1876-1883. doi:10.1249/MSS.0000000000001983

48. Bakker EA, Lee DC, Sui X, et al. Association of resistance exercise, independent of and combined with aerobic exercise, with the incidence of metabolic syndrome. Mayo Clin Proc. 2017;92 (8):1214-1222. doi:10.1016/j.mayocp.2017.02.018

49. Yoo Y-K, Kim S-K, Song M-S. Effects of muscular and aqua aerobic combined exercise on metabolic indices in elderly women with metabolic syndrome. J Exerc Nutrition Biochem. 2013;17(4):133. doi:10.5717/jenb.2013.17.4.133

50. Kim S. The effects of 12 weeks of circuit exercise on obesity, physical fitness and metabolic syndrome index in elderly obese women. J Korean Gerontol Society. 2009;29(3):823-835.

\section{Publish your work in this journal}

Diabetes, Metabolic Syndrome and Obesity: Targets and Therapy is an international, peer-reviewed open-access journal committed to the rapid publication of the latest laboratory and clinical findings in the fields of diabetes, metabolic syndrome and obesity research. Original research, review, case reports, hypothesis formation, expert opinion and commentaries are all considered for publication. The manuscript management system is completely online and includes a very quick and fair peer-review system, which is all easy to use. Visit http://www.dovepress.com/testimonials.php to read real quotes from published authors. 